\title{
Evaluation of Bilateral Asymmetry in the Humerus of Human Skeletal Specimen
}

\author{
Samuel S. Dare $\mathbb{D}^{1},{ }^{1,2}$ Godfery Masilili, ${ }^{1,3}$ Kintu Mugagga, ${ }^{1}$ and Peter E. Ekanem ${ }^{4}$ \\ ${ }^{1}$ Department of Human Anatomy, Faculty of Biomedical Sciences, Kampala International University Western Campus, Uganda \\ ${ }^{2}$ Anatomy Unit, Kabale University School of Medicine, Kabale University, Uganda \\ ${ }^{3}$ Department of Human Anatomy, School of Health Sciences, Makerere University, Uganda \\ ${ }^{4}$ Anatomy Unit, Biomedical Department, Mekelle University, Ethiopia
}

Correspondence should be addressed to Samuel S. Dare; samuel.dare@kiu.ac.ug

Received 28 March 2019; Accepted 2 July 2019; Published 16 July 2019

Academic Editor: Germán Vicente-Rodriguez

Copyright (C) 2019 Samuel S. Dare et al. This is an open access article distributed under the Creative Commons Attribution License, which permits unrestricted use, distribution, and reproduction in any medium, provided the original work is properly cited.

\begin{abstract}
Several studies have established a relationship between morphological and behavioral asymmetry making investigations of bilateral bone asymmetry an attractive and important research area. The purpose of this study was to investigate bilateral asymmetry patterns of skeletal specimen from five geographical locations (Rwanda, Burundi, Congo, Kenya, and Uganda) at Galloway Osteological Collection, Department of Anatomy, School of Biomedical Sciences, Makerere University College of Health Sciences. The angle of torsion and retroversion, mid-shaft circumference, length, and weight of 232 pairs of humeri were determined. A Torsiometer was used to measure the angle of torsion in degrees according to Krahl and Evans 1945, a tape was used to measure the mid-shaft circumference at the level of the apex of the deltoid $\mathrm{V}$, and the length in $\mathrm{cm}$ was determined. An osteometric board was used to measure the length of the humerus in centimeters. A weighing balance was used to measure the weight of the humerus in grams. The analysis of humeral asymmetry with respect to parameters of the human skeletal specimen at the Galloway Osteological Collection Mulago revealed bilateral asymmetrical status observed in the angle of torsion, length, weight, and mid-shaft circumference. Our result mostly showed lateralization to the right in all the parameters investigated except the torsion angle which is to the left. Our investigation revealed that humeral torsion is inversely proportional to weight, length, and mid-shaft circumference of the humerus. This study established the existence of bilateral asymmetries in the humeri of all the geographical regions investigated with more asymmetry observed in the male compared with the female.
\end{abstract}

\section{Introduction}

Symmetry is defined as correspondence in size, shape, and relative position of parts on opposite sides of a dividing line or median plane while asymmetry is described as a lack or absence of symmetry. Although bilateral symmetry in paired morphological traits is evident in humans, significant deviation from this observed in internal organs, human brain, and especially upper limb, is referred to as bilateral asymmetry [1].

Several studies have established a relationship between morphological and behavioral asymmetry making investigations of bilateral bone asymmetry an attractive and important research area [2-4]. This field may help to understand how behavior can influence the dynamic development of bone structure. Bone asymmetry is thought to basically result from disproportionate mechanical stress which influences bone remodeling and plasticity [5, 6]. Krahl et al. 1994 [7], Bass et al. 2002 [8], and Kontulainen et al. 2002 [9] observations of asymmetry between playing and nonplaying arms of tennis players revealed a strong effect of behavioral use of the limbs on diaphyseal structure.

According to Ruff, 2000 [10], it is reasonable to believe that more active humans characterized by activities that are greatly influenced by mechanical stressors in life demonstrate greater asymmetry. Though genetic constitution may play some little role, external factors are believed to be major determinant of bilateral asymmetry. Studies have reported sex differences in bilateral asymmetry but results are not consistent depending on the skeletal sample and element $[2,11]$ 
Asymmetry between the upper limbs bones have been reported in previous studies with little differences in all races and difference significantly greater in males than females [1215]. In most cases the left bones have been reported to be more variable in weight and length but the average lateral asymmetry was to the right in the arms. According to Latimer and Lowrance [16] in the study of the weights and lengths of right and left bones of each pair from 105 human skeletons from Asia, all of the long bones of the upper limb were heavier and longer on the right side and the humerus was most asymmetric.

The examination of the upper and lower limb asymmetries can be useful to medical scientists, archeologists, anthropologists [17, 18], and police and forensic experts and for medicolegal studies $[19,20]$. Significantly, this intraindividual variation in the size and shape of the left and right sides of the body has been linked with low back pain [21, 22]. Al-Eisa et al. [22] showed that the higher the degree of asymmetry in the upper and lower limbs, the greater the likelihood of low back pain.

The consistent use of a limb habitually over the other during bimanual activities without a pathological condition results in asymmetric increase in the mechanical load of the preferred hand and limb dominance (handedness) [23, 24]. Studies on past populations which examined paired elements of the human skeleton for bilateral asymmetry thought that it was sexually dimorphic and associated handedness with dominant upper [25].

Past studies have established a relationship between hand dominance and side of asymmetric disease with right-handed individuals prone to more serious disease on the right side of the body.

Body parts asymmetry such as forehead, facial structures, cubital and popliteal crease, and thumbs has been found to be common in patients with localization related epilepsy syndromes.

Fong et al. 2003 [26] study of patients with seizure disorders concluded that body asymmetries constitute a useful clue to diagnosis of localization related seizure and may provide clues for lateralizing seizure origin in partial onset seizures.

Singh [27] showed bilateral asymmetry in the direction and degree of torsion in metacarpal bones. According to Whiteley [28], "the development of humeral torsion seems to be determined by hereditary and activity-related factors $[29,30]$, with relative contribution remaining unknown". It is hypothesized that for the majority of adults, humeral torsion is largely genetic in origin, with opportunity available for activity-related influences of a less magnitude.

The purpose of this study was to investigate bilateral asymmetry patterns of skeletal specimen from five geographical locations (Rwanda, Burundi, Congo, Kenya, and Uganda) at Galloway Osteological Collection, Department of Anatomy, School of Biomedical Sciences, Makerere University College of Health Sciences.

\section{Materials and Methods}

This study was done at Galloway Osteological Collection, Department of Anatomy, School of Biomedical Sciences,

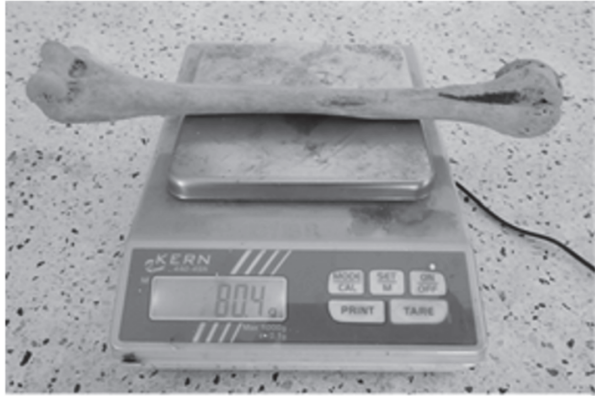

FIgURE 1: Measurement of humeral weight using a digital (KERN 440-45N) machine.

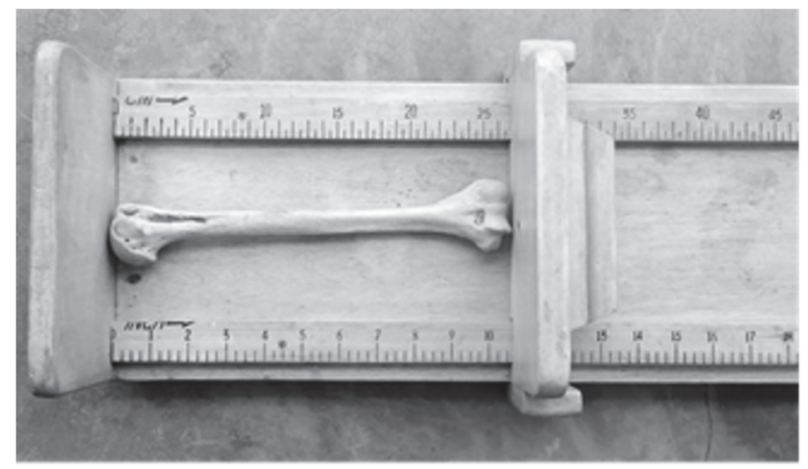

FIGURE 2: Measurement of humeral length using an osteometric board.

Makerere University College of Health Sciences. It consists of over 232 sets of skeletons, both female and male, of different ages and geographical origins. It was cross-sectional descriptive and quantitative study involving measurements.

2.1. Determination of Humeral Weight. A weighing balance with a margin of error of $+/-0.1$ was used to measure the weight of the humerus in grams (g), Figure 1.

2.2. Determination of Humeral Length. An osteometric board with a narrow margin of error of $+/-0.1$ was used to measure the length of the humerus in centimeters $(\mathrm{cm})$ by placing the bone horizontally on the board, Figure 2 .

2.3. Determination of Mid-Shaft Circumference. A millimeter graph paper was used to measure the mid-shaft circumference at the level of the apex of the deltoid $\mathrm{V}$ in centimeters $(\mathrm{cm})$, Figure 3.

2.4. Determination of Angle of Torsion. A Torsiometer was used to measure the angle of torsion in degrees according to Dare et al., 2012 [31], Figure 4.

\section{Data Analysis}

Data collected was analyzed scientifically using GraphPad Prism 7. All data was expressed as Mean $+/$ - SEM. The data was analyzed using correlation coefficient and paired 


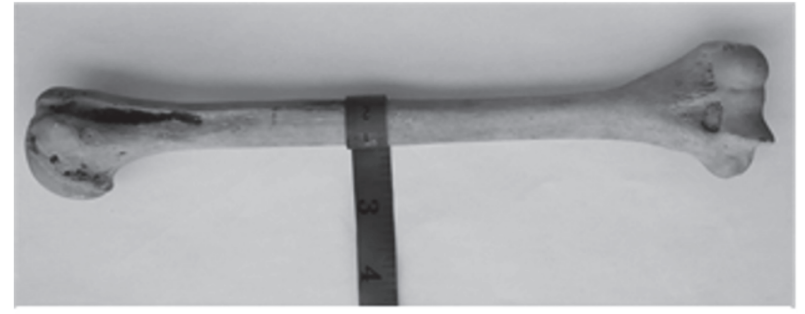

FigURE 3: Measurement of humeral mid-shaft circumference using a measuring tape.

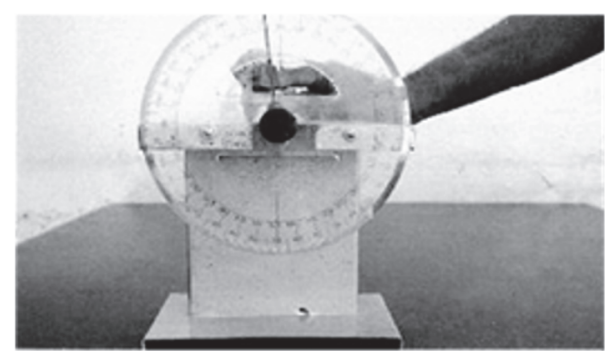

Figure 4: Measurement of humeral angle of torsion using a Torsiometer.

sample t-test with multiple comparisons. A P-value of $<0.05$ is considered as significant.

\section{Results}

The analysis of humeral asymmetry with respect to parameters of the human skeletal specimen at the Galloway Osteological Collection Mulago revealed bilateral asymmetrical status observed in the angle of torsion, length, weight, and mid-shaft circumference. The coefficient of correlation between parameters and $p$ values were expressed as " $r$ " and "p", respectively.

\section{Discussion}

Differences have been observed within or between body structures such as the size and shape of limb bones. According to $[23,32,33]$ healthy individuals present mild directional asymmetry which may result, for example, from increased mechanical stress of the preferred limb over the other during habitual activities. Several parameters of the body long bones such as weight and length may reveal the degree of asymmetry. Steel and Mays [34] measured the maximal length of the humerus, radius, and ulnar in a series of 271 skeletons from medieval osteological collection and reported the presence of oriented asymmetry in the arm bone length.

In our study, we measured the length, weight, torsion angle, and mid-shaft circumference of the humerus in order to investigate the presence of bilateral asymmetry in different geographical locations. Our result shows that the male and female right humerus are heavier than the left ones in all

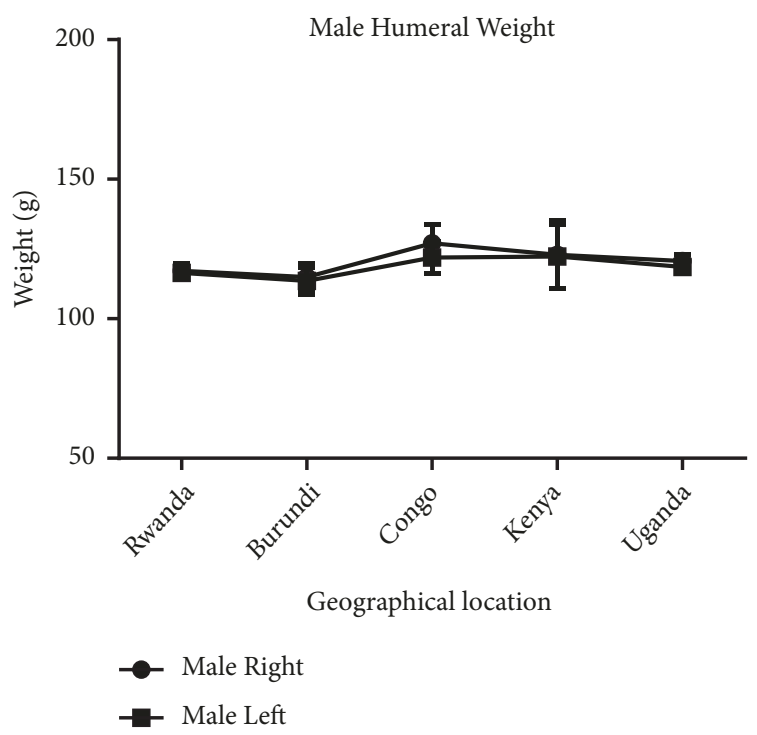

(a)

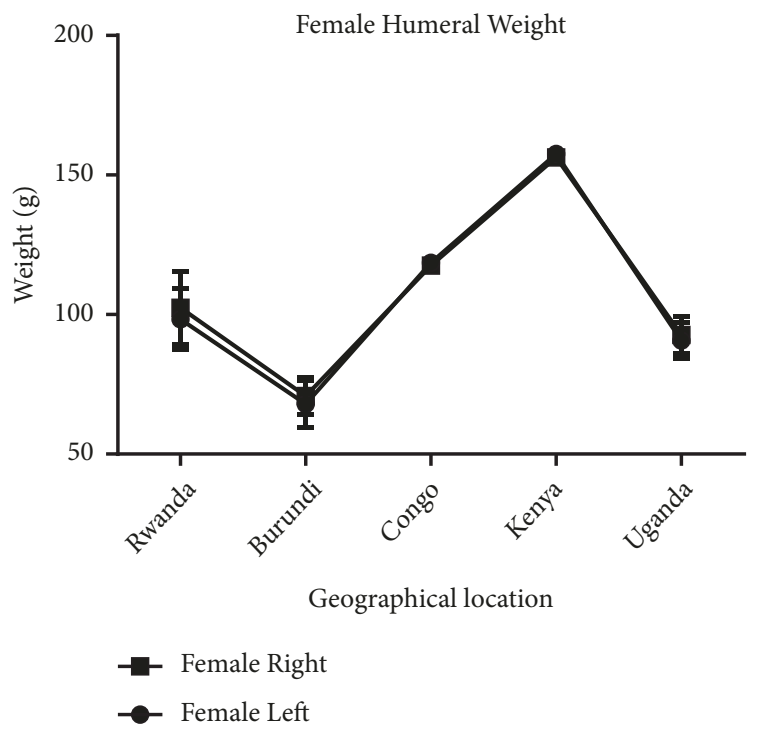

(b)

FIGURE 5: The male and female right and left humeral weight across the geographical locations. (a) The right humerus is heavier than the corresponding left one in all locations; correlation coefficient $\mathrm{r}=0.94$ and $\mathrm{p}=0.019$. (b) The right humerus is slightly heavier than the left one in Rwanda, Burundi, and Uganda while the left humerus is slightly heavier than the right one in Congo and Kenya; $r=0.99$ and $p=0.00004$. The error bars represent the standard deviation of measurements for number of specimens measured (n) per geographical location.

the geographical locations except in the Congo and Kenya female humerus where the left was heavier than the right one (Figure 5). This is consistent with previous studies which reported that the long bones of the upper limb are heavier on the right side $[16,35]$. The disparity observed in Congo and Kenya female may be due to fewer sample size and therefore cannot be conclusive. In Figure 6, showing the comparison of male and female corresponding right and left humeral weight, 


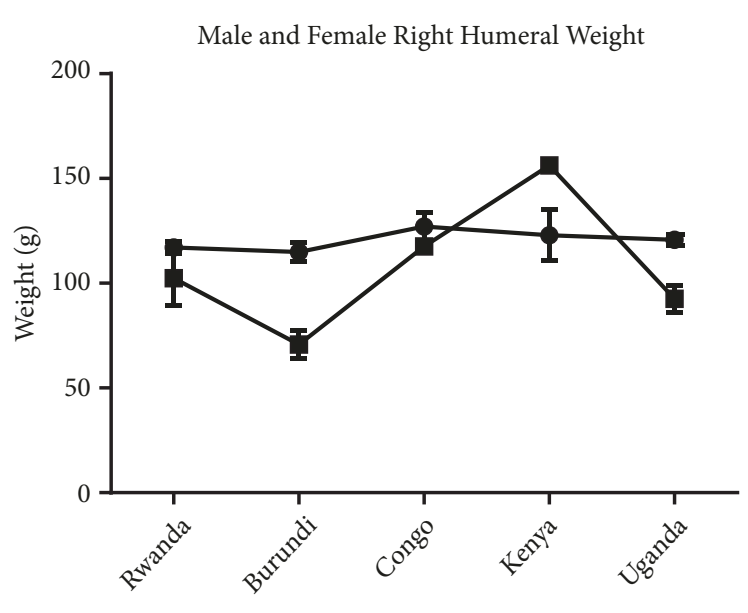

Geographical location

- Male Right

Female Right

(a)

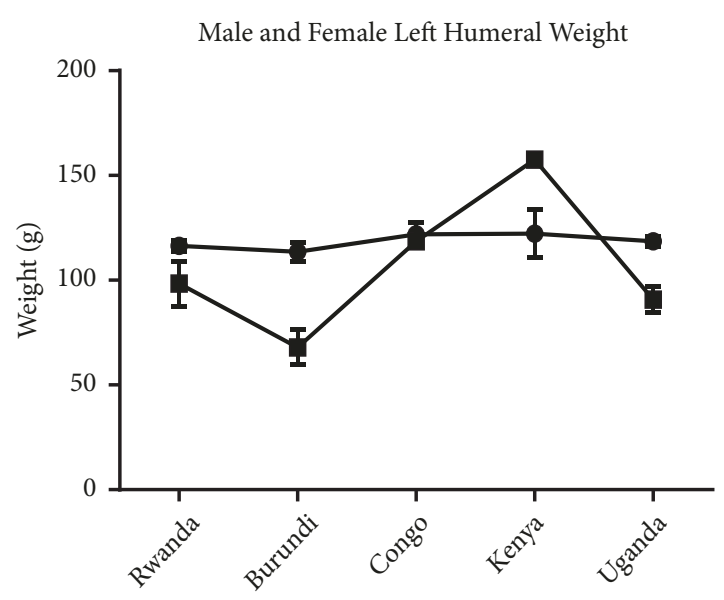

Geographical location

Male Left

Female Left

(b)

FIGURE 6: A comparison between male and female humeral weight across the geographical regions. (a) The right male humerus is slightly higher in all regions except Kenya where the right female is slightly higher than the male one; $r=0.66$ and $p=0.22$ (b) The left male humerus is slightly heavier in all regions except Kenya where the left female is slightly higher than the male one; $r=0.88$ and $p=0.04$. The error bars represent the standard deviation of measurements for number of specimens measured (n) per geographical location.

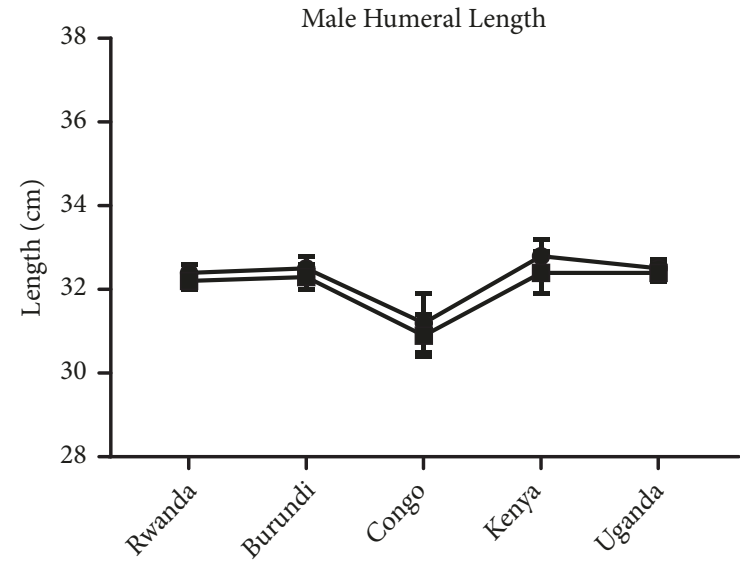

Geographical location

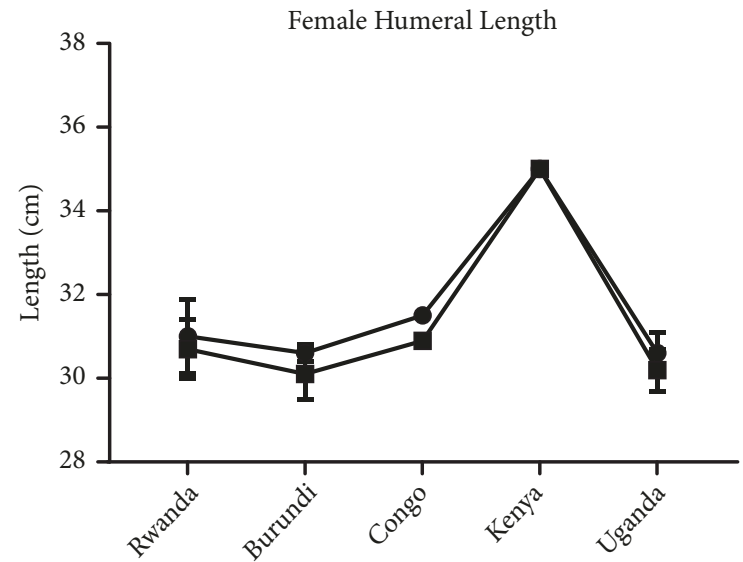

Geographical location

Female Right

Female Left

(a)

(b)

FIGURE 7: The male and female right and left humeral length across the geographical locations. (a) The right male humerus is longer than the corresponding left one in all the geographical locations; $r=0.98$ and $p=0.002$. (b) The right female humerus is longer than the left one in all locations except Kenya where the right is equal to the left one; $r=0.99$ and $p=0.0001$. The error bars represent the standard deviation of measurements for number of specimens measured (n) per geographical location.

our result revealed heavier right humeri in the male in all the geographical locations except in Kenya female which has a heavier humerus on the left compared to the right one. This right-sided asymmetry in humeral weight may be attributed to more frequent use of the right arm resulting in heavier or stronger muscles of that side and consequently heavier and stronger bones [36].
Measurement of humeral length revealed longer right humeri in all geographical locations in both male and female except in Kenya where both male and female are of equal length. Comparison of male and female corresponding right and left sides shows a longer humerus in the male in all geographical locations except Kenya which shows the opposite (Figures 7 and 8). This observation in humeral 
Male and Female Right Humeral Length

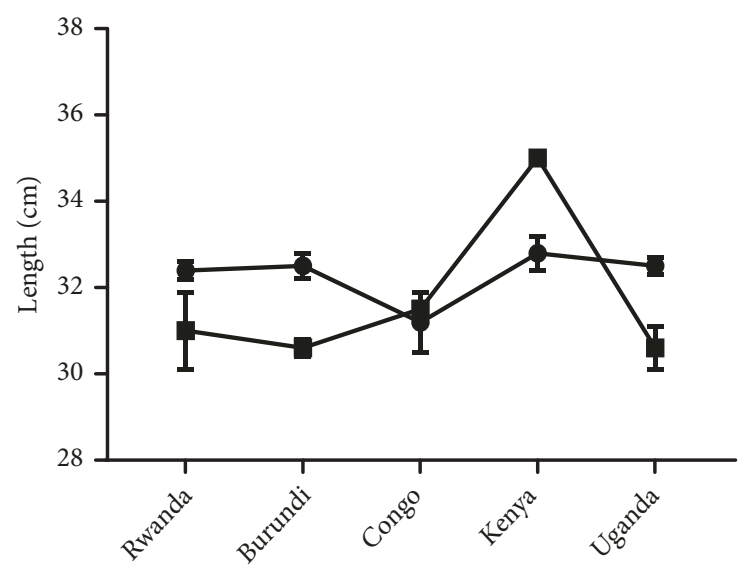

Geographical location

Male Right

Female Right

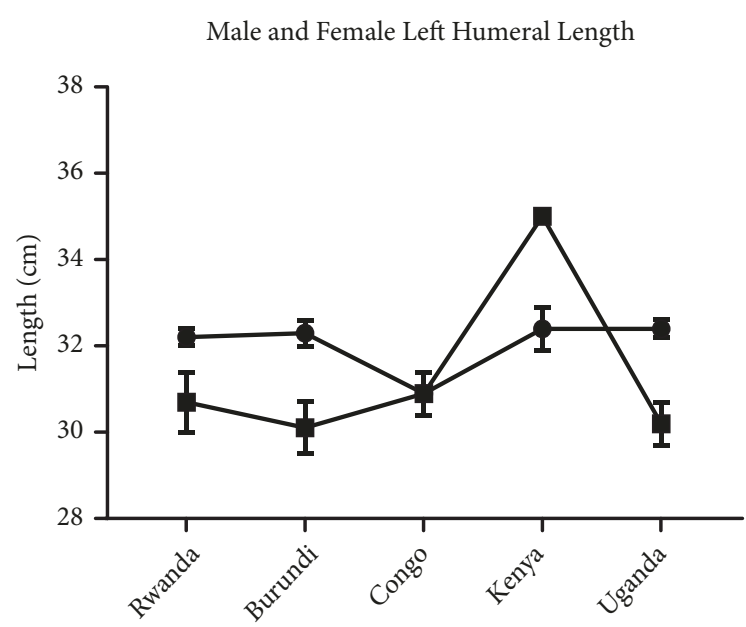

Geographical location

Male Left

Female Left

(a)

(b)

FIGURE 8: A comparison between male and female humeral length across the geographical regions. (a) The right male humerus is longer in all regions except Kenya where the right female is longer than the male one; $r=0.3$ and $p=0.63$. (b) The left male humerus is longer in all regions except Kenya where the left female is longer than the male one; $r=0.19$ and $p=0.76$. The error bars represent the standard deviation of measurements for number of specimens measured (n) per geographical location.

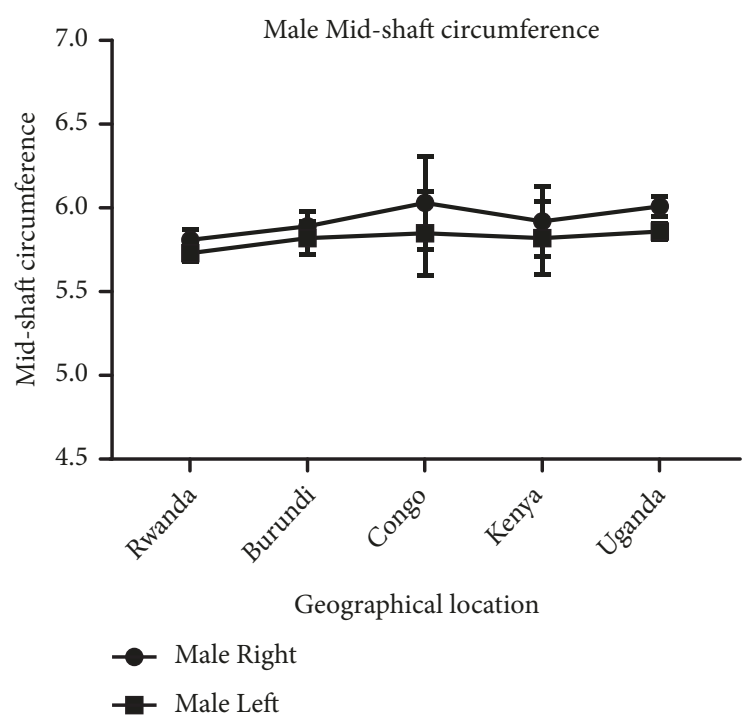

(a)

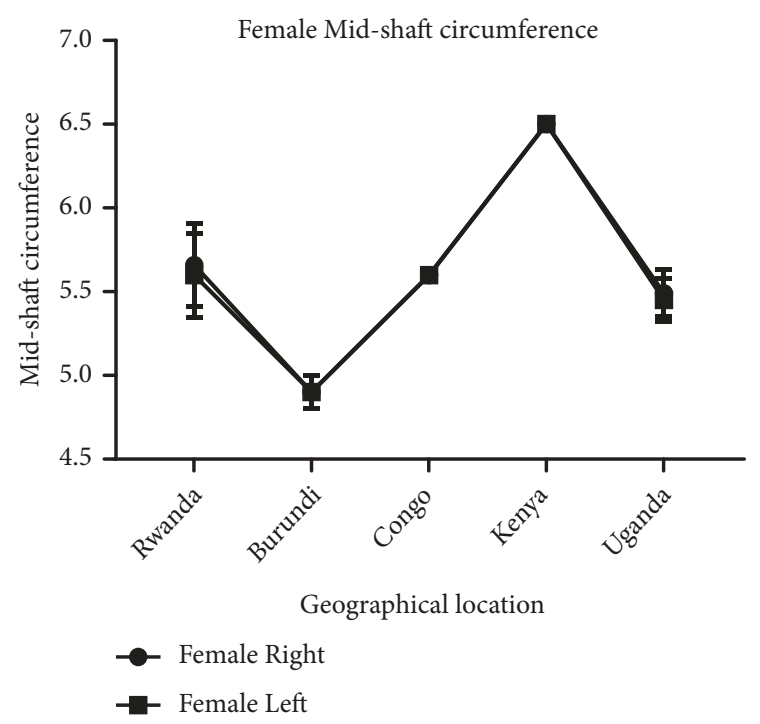

(b)

Figure 9: This chart shows the male and female right and left mid-shaft circumference of the humerus across the geographical locations. (a) The right male humerus is thicker than the corresponding left one in all the geographical locations; $r=0.92$ and $p=0.026$. (b) The right female humerus is thicker than the left one in all locations except Kenya where the right is equal to the left one; $r=0.99$ and $p=0.00005$. The error bars represent the standard deviation of measurements for number of specimens measured (n) per geographical location.

length is in agreement with the reports of Cuk et al. [3] and Barros \& Soligo [37] which showed that average lateral asymmetry in the arms was to the right and that humans are unique in being lateralized to the right. Looking at the measurement of the mid-shaft circumference (Figures 9 and 10), we also observed higher values on the right humeri in all the geographical locations except in Congo and Kenya female which have equal values on both right and left humeri (Tables 1 and 2). These observations are similar to that of humeral weight with similar disparities. Furthermore, measurement of humeral torsion angle revealed an interesting phenomenon where angle of torsion is greater on all male left humeri except 


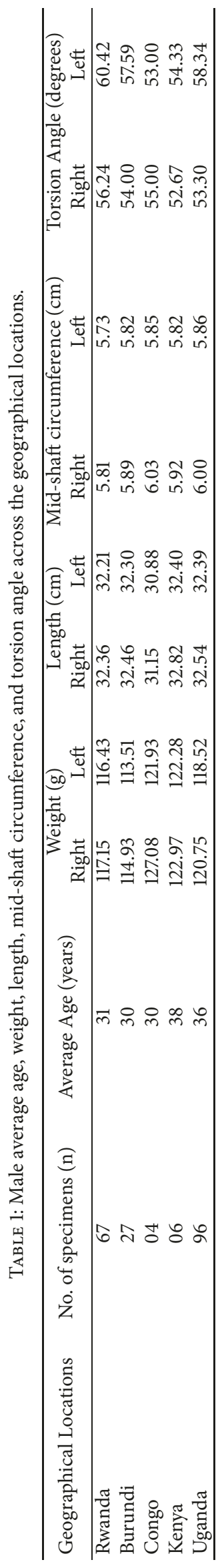




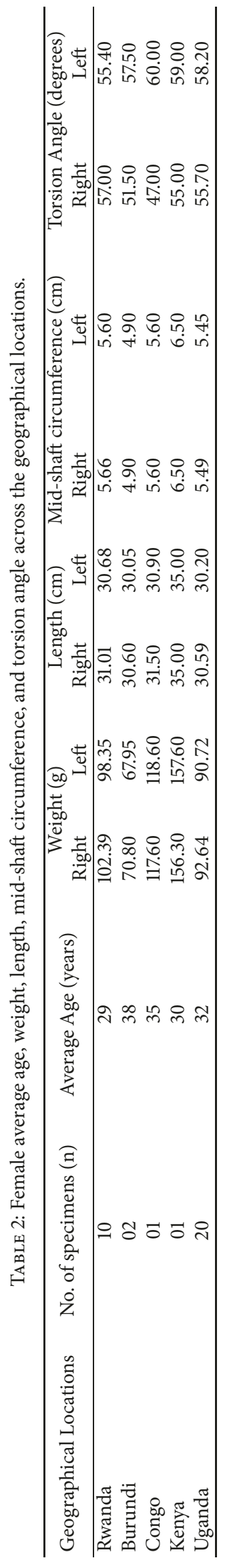



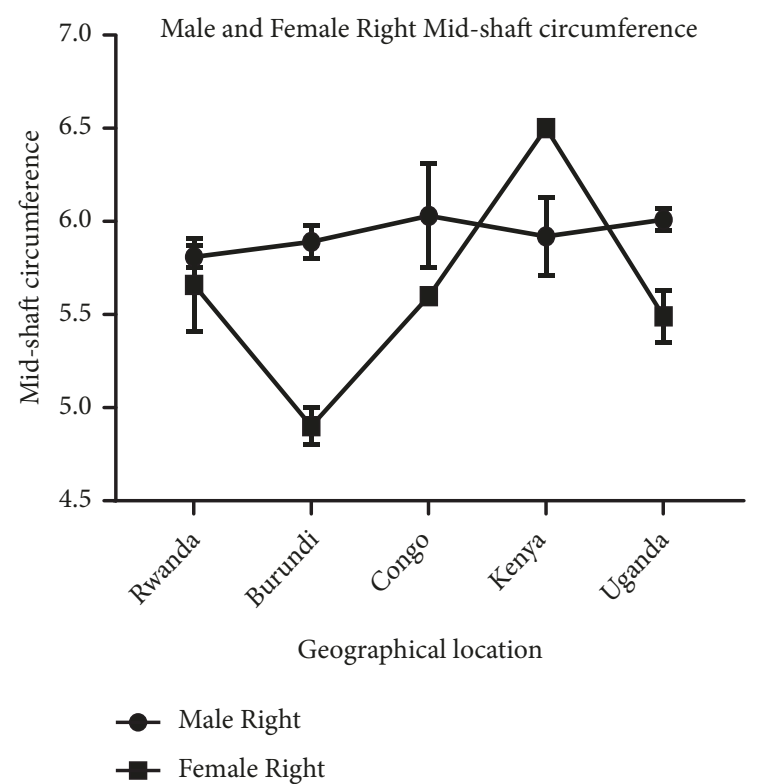

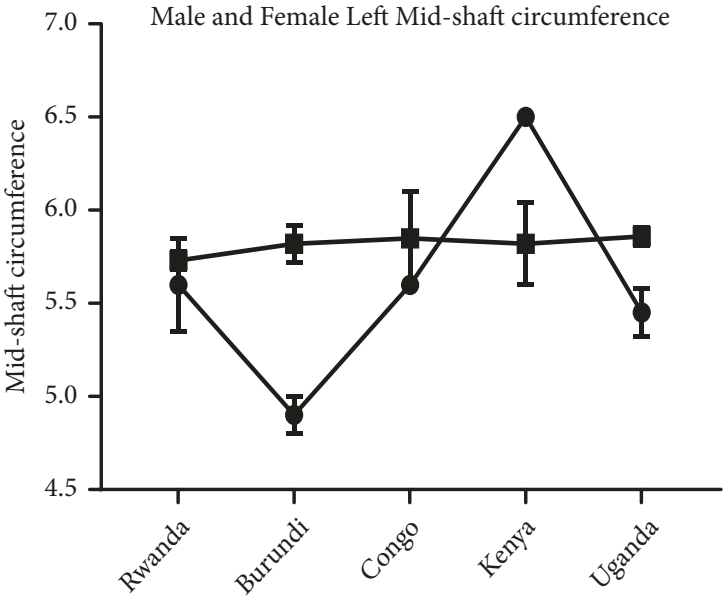

Geographical location

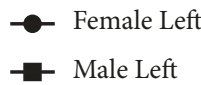

(a)

(b)

Figure 10: A comparison between male and female mid-shaft circumference of the humerus across the geographical regions. (a) The right male humerus is slightly thicker in all regions except Kenya where the right female is slightly thicker than the male one; $r=0.013$ and $p=0.98$. (b) The left male humerus is slightly thicker in all regions except Kenya where the left female is slightly thicker than the male one; $r=-0.049$ and $\mathrm{p}=0.94$. The error bars represent the standard deviation of measurements for number of specimens measured (n) per geographical location.

in Congo having a greater torsion angle on the right. The female specimen presents greater torsion angle on the left in all locations except Rwanda where angle of torsion is greater on the right. Burundi, Kenya, and Uganda showed consistent greater torsion on the left humerus compared to the right one in both sexes. On the contrary, Rwanda shows greater right torsion in male while Congo shows greater left torsion in female (Figures 11 and 12). Our study therefore contradicted the report of Barros and Soligo [37] which stated that both the magnitude and direction of asymmetries in humeral torsion in paired humeri from humans are unique in being lateralized to the right. However, in all the parameters measured in this study, we observed that right humerus in both sexes in most cases presented larger values compared with the left one except the angle of torsion which is variable. This right-sided asymmetry may result from the normal tendency of individuals to favor the right upper limb during power activities [36].

According to our result, there is a strong correlation between the right and left humeral weight, length, and midshaft circumference, but a slightly weak correlation in the torsion angle across the geographical locations (Figures 5, 7, 9, and 11). Comparison between right and left sides of both sexes shows a strong correlation in humeral weight (Figure 6), weak correlation in humeral length and mid-shaft circumference in male (Figures 8 and 10), and no correlation in female mid-shaft circumference as well as humeral torsion angle in both sexes (Figures 10 and 12).

According to Steel and Mays [34], "the proportion of people with longer right or left long arm bones in the medieval population agreed with the proportion of right or left handers in modern population". It was established that the main cause of oriented asymmetry is right or left handedness in that the arm subjected to greater mechanical stress as a result of use becomes the dominant. Generally, without a particular pathological condition, differential loading is most often a reflection of limb dominance (handedness) [23].

The findings have established that ipsilateral, as well as contralateral, movements activate the left, but not the right, motor cortex or associated areas of either hemisphere. Investigation of patients with damaged brain shows that the left hemisphere in right handers is specialized for controlling cognitive motor tasks in both arms. In the light of this, future studies are needed to investigate the mechanisms for this asymmetry and to possibly establish a relationship between humeral asymmetry and anatomical characteristics of the brain.

\section{Conclusion}

This study established the existence of bilateral asymmetries in the humerus of all the geographical regions investigated with more asymmetry observed in the male compared with the female. The asymmetry is to the right in the weight, length, and mid-shaft circumference while the asymmetry is to the left in torsion angle. Also, our investigation revealed that humeral torsion is inversely proportional to weight, length, and mid-shaft circumference of the humerus. 


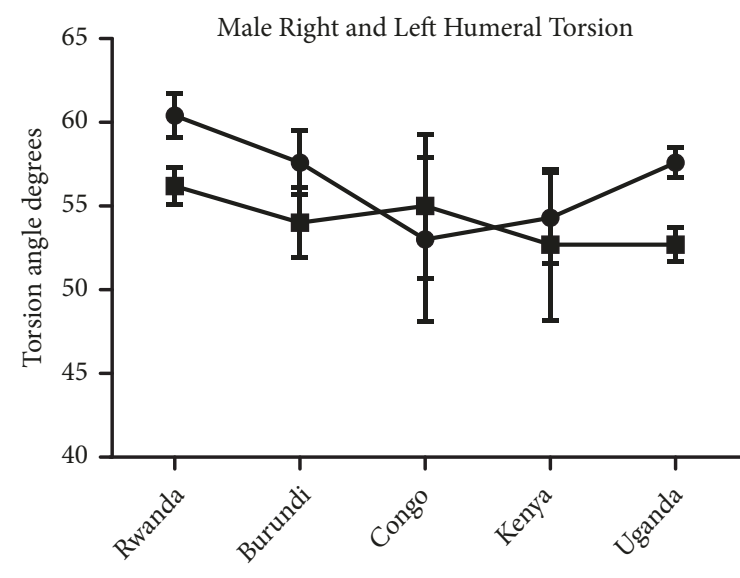

Geographical location

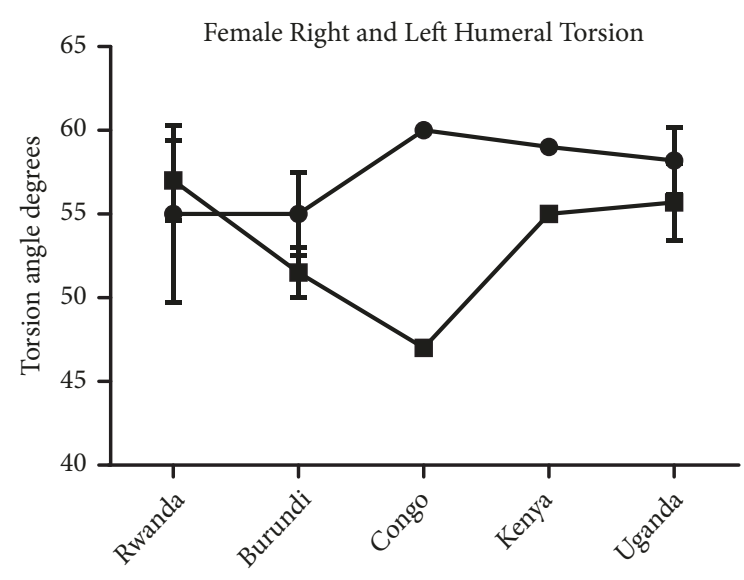

Geographical location

Female Right

Female Left

Male Right

Male Left

(a)

(b)

Figure 11: The male and female right and left humeral torsion across the geographical locations. (a) The right male humerus is less than the corresponding left one in both sexes across all the geographical locations except Congo where the right is more than the left one; $\mathrm{r}=0.36$ and $\mathrm{p}=0.55$. (b) The right female humerus is less than the left one in all locations except Rwanda where the right is more than the left one; $r=$ 0.44 and $\mathrm{p}=0.46$. The error bars represent the standard deviation of measurements for number of specimens measured (n) per geographical location.

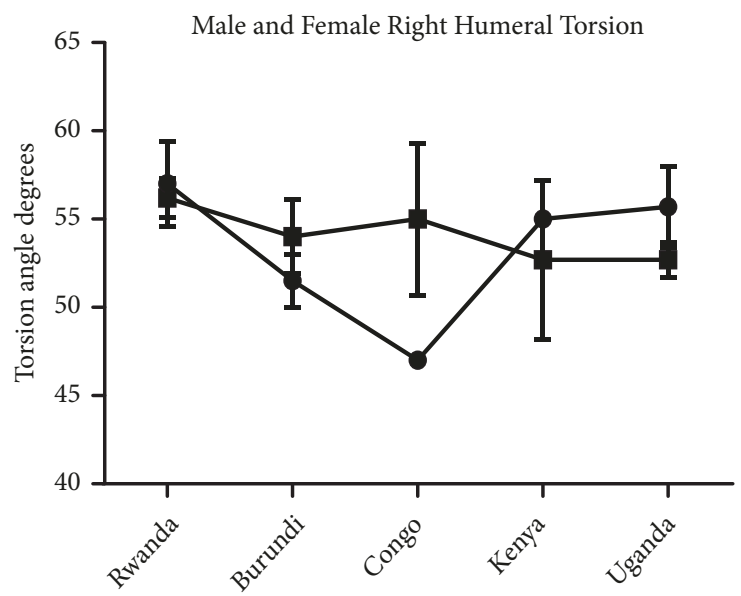

Geographical location

Male Right

Female Right

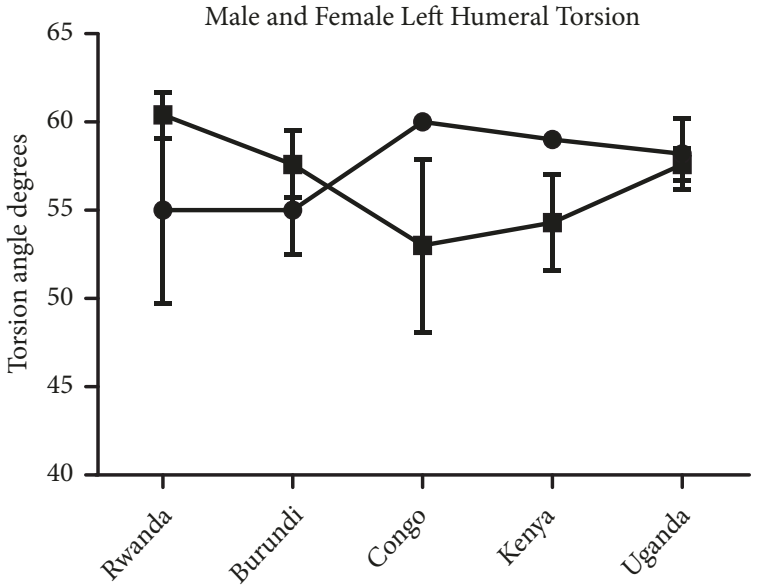

Geographical location

Male Left

Female Left

(a)

(b)

FIGURE 12: Comparison between male and female right and left humeral torsion across the geographical regions. (a) The right female torsion angle is more than the male one in Rwanda, Kenya, and Uganda while the right male torsion is more than the female one in Burundi and Congo; $r=-0.14$ and $p=0.82$. (b) The left female torsion is more than the male one in Congo, Kenya, and Uganda while the left male torsion is more than the female one in Rwanda and Burundi; $r=-0.87$ and $p=0.055$. The error bars represent the standard deviation of measurements for number of specimens measured (n) per geographical location.

\section{Data Availability}

The metadata used to support the findings of this study are available from the corresponding author upon request.

\section{Conflicts of Interest}

The authors declare that there are no conflicts of interest regarding the publication of this paper 


\section{Acknowledgments}

The researchers wish to acknowledge Department of Human Anatomy, Kampala International University Western Campus, and Department of Human Anatomy, School of Health Sciences, Makerere University, for giving access to the bones in the Osteological Collection Museum.

\section{References}

[1] Z. F. Zaidi, "Body asymmetries: incidence, etiology and clinical implications," Australian Journal of Basic and Applied Sciences, vol. 5, no. 9, pp. 2157-2191, 2011.

[2] J. Steele, "Handedness in past human populations: skeletal markers," Laterality, vol. 5, no. 3, pp. 193-220, 2000.

[3] C. Tonka, P. Leben-Seliak, and M. Stefancic, Lateral Asymmetry of the Human Long Bones, Variability and Evolution 9, 2001.

[4] R. A. Lazenby, "Skeletal biology, functional asymmetry and the origins of 'handedness,' Journal of Theoretical Biology, vol. 218, no. 1, pp. 129-138, 2002.

[5] E. Trinkaus, S. E. Churchill, and C. B. Ruff, "Postcranial robusticity inHomo. II: humeral bilateral asymmetry and bone plasticity," American Journal of Physical Anthropology, vol. 93, no. 1, pp. 1-34, 1994.

[6] S. E. Churchill and V. Formicola, "A case of marked bilateral asymmetry in the upper limbs of an upper palaeolithic male from barma grande (liguria) Italy," International Journal of Osteoarchaeology, vol. 7, no. 1, pp. 18-38, 1997.

[7] H. Krahl, U. Michaelis, H. Pieper, G. Quack, and M. Montag, "Stimulation of bone growth through sports," The American Journal of Sports Medicine, vol. 22, no. 6, pp. 751-757, 1994.

[8] S. L. Bass, L. Saxon, R. M. Daly et al., "The effect of mechanical loading on the size and shape of bone in pre-, peri-, and postpubertal girls: a study in tennis players," Journal of Bone and Mineral Research, vol. 17, no. 12, pp. 2274-2280, 2002.

[9] S. Kontulainen, H. Sievänen, P. Kannus, M. Pasanen, and I. Vuori, "Effect of long-term impact-loading on mass, size, and estimated strength of humerus and radius of female racquetsports players: a peripheral quantitative computed tomography study between young and old starters and controls," Journal of Bone and Mineral Research, vol. 17, no. 12, pp. 2281-2289, 2002.

[10] C. B. Ruff, "Biomechanical analyses of archaeological human skeletal samples," in Biological Anthropology of the Human Skeleton, M. A. Katzenburg and S. R. Saunders, Eds., pp. 71-102, Alan R. Liss, Inc., New York, NY, USA, 2000.

[11] C. B. Ruff and H. H. Jones, "Bilateral asymmetry in cortical bone of the humerus and tibiadsex and age factors," Human Biology, vol. 53, pp. 69-86, 1981.

[12] E. Warren, "An investigation on the variability of the human skeleton with especial reference to the naqada race, discovered by professor flinders petrie in his explorations in Egypt," Proceedings of the Royal Society of London, vol. 61, pp. 398-401, 1897.

[13] A. H. Schultz, "Proportions, variability, and asymmetries of the long bones of limbs and the clavicles in man and apes," Human Biology, vol. 9, pp. 281-328, 1937.

[14] Y. Hiramoto, "Right-left differences in the lengths of human arm and leg bones," Acta Anatomica Nipponica, vol. 68, no. 5, pp. 536-543, 1993.

[15] T. D. White and P. A. Folkens, The Human Bone Manual, Elsevier Academic Press, New York, NY, USA, 1st edition, 2005.
[16] H. B. Latimer and E. W. Lowrance, "Bilateral asymmetry in weight and in length of human bones," The Anatomical Record, vol. 152, no. 2, pp. 217-224, 1965.

[17] M. İşcan and D. Shihai, "Sexual dimorphism in the Chinese femur," Forensic Science International, vol. 74, no. 1-2, pp. 79-87, 1995.

[18] C. A. King, M. Y. İşcan, and S. R. Loth, "Metric and comparative analysis of sexual dimorphism in the thai femur," Journal of Forensic Sciences, vol. 43, no. 5, pp. 954-958, 1998.

[19] M. Steyn and M. Y. Işcan, "Osteometric variation in the humerus: sexual dimorphism in South Africans," Forensic Science International, vol. 106, no. 2, pp. 77-85, 1999.

[20] G. Mall, M. Hubig, A. Büttner, J. Kuznik, R. Penning, and M. Graw, "Sex determination and estimation of statue from long bones of the arm," Journal Forensic Science International, vol. 117, no. 1-2, pp. 23-30, 2001.

[21] O. Friberg, "Clinical symptoms and biomechanics of lumbar spine and hip joint in leg length inequality," The Spine Journal, vol. 8, no. 6, pp. 643-651, 1983.

[22] E. Al-Eisa, D. Egan, and R. Wassersug, "Fluctuating asymmetry and low back pain," Evolution and Human Behavior, vol. 25, no. 1, pp. 31-37, 2004.

[23] T. A. Roy, C. B. Ruff, and C. C. Plato, "Hand dominance and bilateral asymmetry in the structure of the second metacarpal," American Journal of Physical Anthropology, vol. 94, no. 2, pp. 203-211, 1994.

[24] M. T. Cassandra, Quantifying Dominance: An Analysis of Humeral Bilateral Asymmetry and Implications for Behavioral Reconstruction, University of Pennsylvania, 2012, http://repository .upenn.edu/cgi/viewcontent.cgi article=1055\&amp; context $=$ anthro_seniortheses.

[25] E. Jaskulska, "Skeletal bilateral asymmetry in a medieval population from Deir an-Naqlun (Nekloni), Egypt," Bioarchaeology of the Near East, vol. 3, pp. 17-26, 2009.

[26] G. Fong, Y. F. Mak, B. E. Swartz, G. O. Walsh, and A. V. DelgadoEscueta, "Body part asymmetry in partial seizure," European Journal of Epilepsy, vol. 12, no. 8, pp. 606-612, 2003.

[27] I. Singh, "Torsion in metacarpal bones and bilateral asymmetry," Journal of Anatomy, vol. 129, no. 2, pp. 343-349, 1979.

[28] R. Whiteley, Humeral Torsion and Throwing [Ph.D. thesis], University of Sydney, 2009, http://www.4shared.com/document/pP88gLuq/Thesis_Final.html.

[29] G. Edelson, "The development of humeral head retroversion," Journal of Shoulder and Elbow Surgery, vol. 9, no. 4, pp. 316-318, 2000.

[30] V. E. Krahl, "The torsion of the humerus; its localization, cause and duration in man," American Journal of Anatomy, vol. 80, no. 3, pp. 275-319, 1947.

[31] S. S. Dare, M. G. Masilili, G. Okumu, Y. G. Mohammed, S. Abba, and A. O. Okpanachi, "Determination of angles of torsion and retroversion of the humerus of male and female skeleton specimens in Uganda," Asian Journal of Medical Sciences, vol. 4, no. 5, pp. 174-178, 2012.

[32] I. Ercan, S. T. Ozdemir, A. Etoz et al., "Facial asymmetry in young healthy subjects evaluated by statistical shape analysis," Journal of Anatomy, vol. 213, no. 6, pp. 663-669, 2008.

[33] K. Schaefer, T. Lauc, P. Mitteroecker, P. Gunz, and F. L. Bookstein, "Dental arch asymmetry in an isolated adriatic community," American Journal of Physical Anthropology, vol. 129, no. 1, pp. 132-142, 2006. 
[34] J. Steele and S. Mays, "Handedness and directional asymmetry in the long bones of the human upper limb," International Journal of Osteoarchaeology, vol. 5, no. 1, pp. 39-49, 1995.

[35] B. Gutnik, A. Skurvydas, A. Zuoza et al., "Evaluation of bilateral asymmetry between upper limb masses in right-handed young adults of both sexes," Perceptual and Motor Skills, vol. 120, no. 3, pp. 804-815, 2015.

[36] K. Krishan, "Marked limb bilateral asymmetry in an agricultural endogamous population of North India," American Journal of Human Biology, vol. 23, no. 5, pp. 674-685, 2011.

[37] A. Barros and C. Soligo, "Bilateral asymmetry of humeral torsion and length in African apes and humans," Folia Primatologica, vol. 84, no. 3-5, pp. 220-238, 2013. 


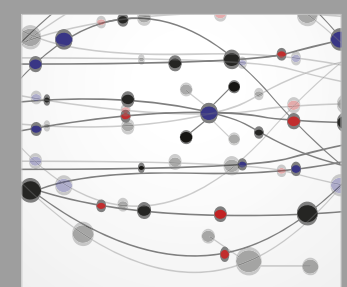

The Scientific World Journal
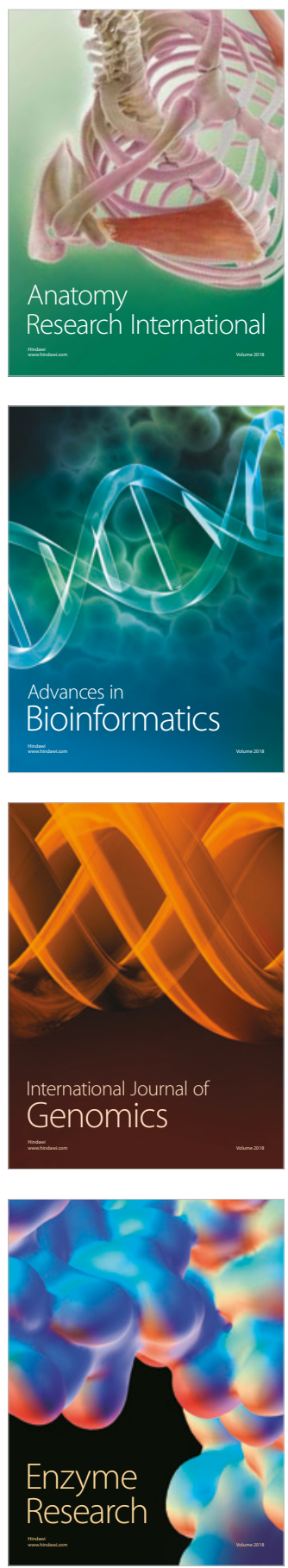
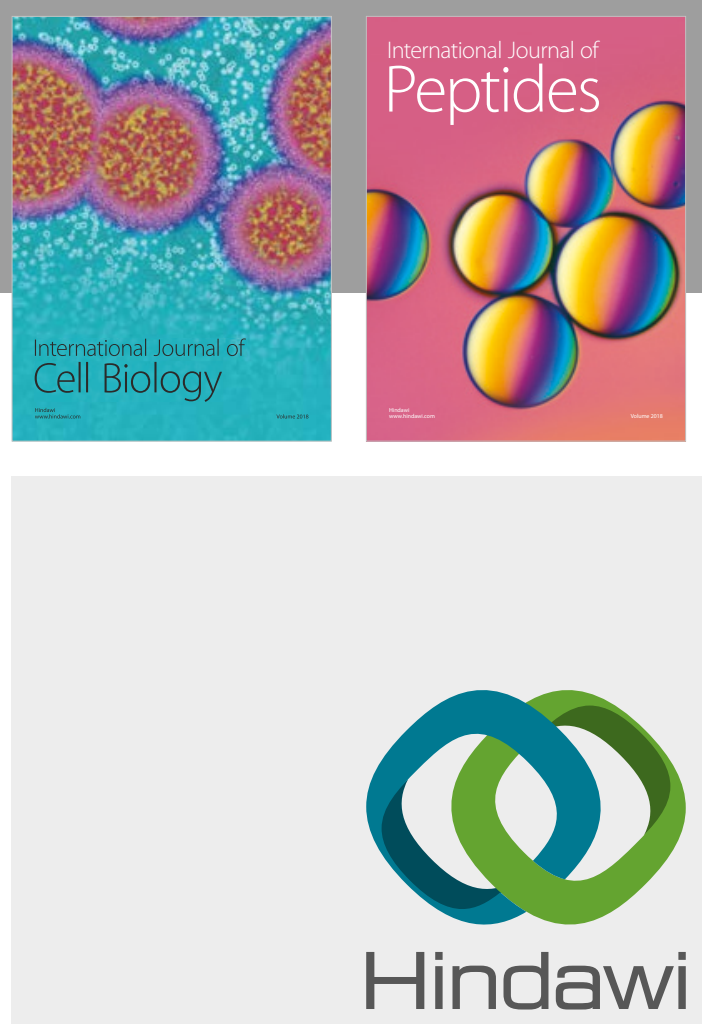

Submit your manuscripts at

www.hindawi.com
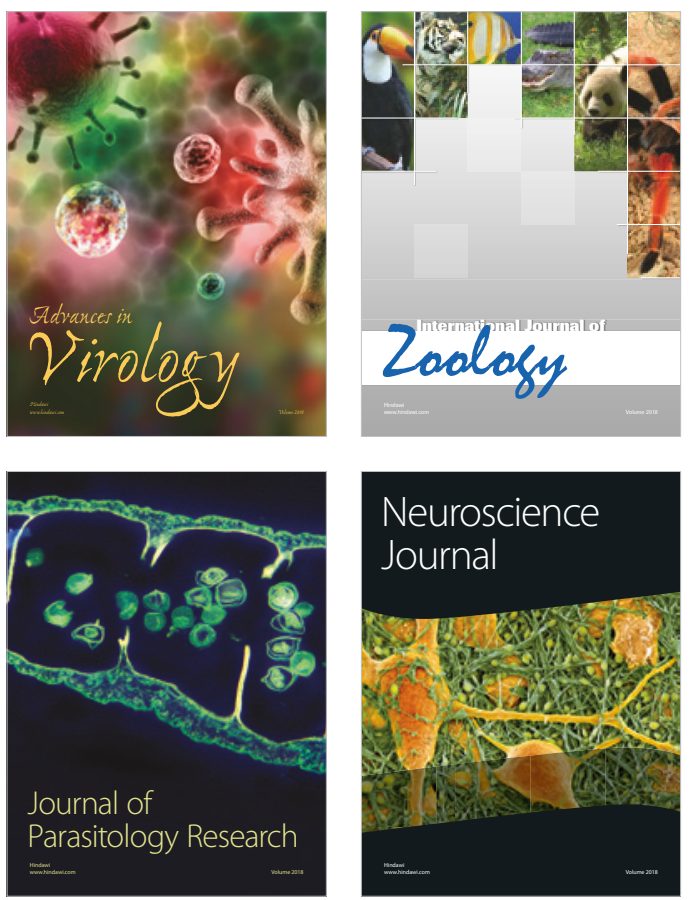
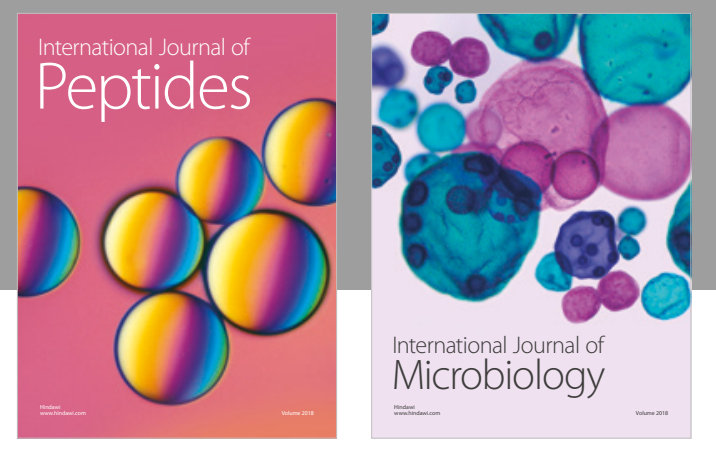

nternational Journal of Microbiology
Journal of
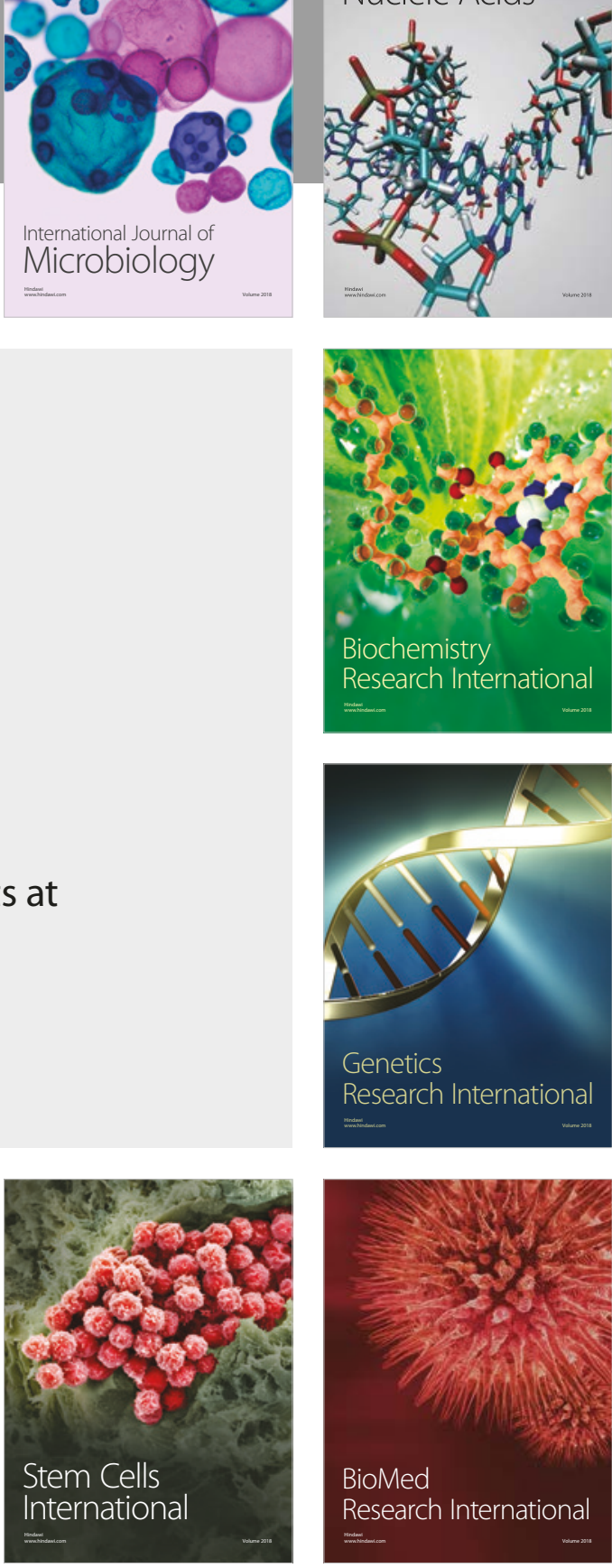
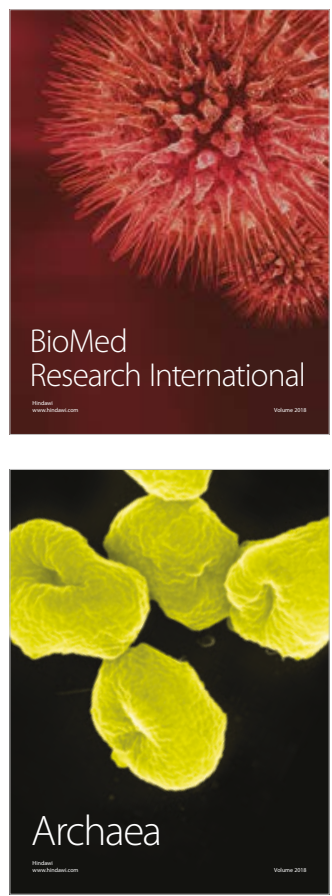